\title{
NODULAÇÃO E CRESCIMENTO DE 49 LEGUMINOSAS ARBÓREAS NATIVAS DA AMAZÔNIA EM VIVEIRO(1)
}

\author{
F. M. S. MOREIRA ${ }^{(2)}$
}

\begin{abstract}
RESUMO
Os ecossistemas periodicamente inundados, embora representem $25 \%$ da área total da Amazônia, contribuem com $75 \%$ da produção madeireira. Tanto esses ecossistemas como os de terra firme apresentam grande diversi dade de espécies da família Leguminosae. Algumas dessas espécies já são exploradas economicamente de forma extrativista, mas o potencial econômico da maioria permanece inexplorado. Conhecer o comportamento dessas espécies em condições de viveiro é o primeiro passo para compreender sua biologia e estabelecer plantios nas áreas já desmatadas. Neste trabalho, desenvolvido no Campus do INPA, em Manaus, durante 1985 e 1986, são apresentadas informações sobre o crescimento inicial e nodulação de 49 espécies arbóreas nativas, de ecossistemas de terra firme (16) ou periodicamente inundados, (33) da Amazônia. Plântulas recém-germinadas foram transplantadas, em condições de viveiro, para sacos plásticos que continham cinco diferentes substratos que consistiram de areia adubada, de uma mistura de argila com areia 3:2 (v/v), de material do horizonte A de um glei húmico, e de material do horizonte $A$ de um podzólico vermel ho-amarelo, adubado ou não. A maioria das espécies desenvolveuse bem nos cinco substratos. Algumas espécies cresceram melhor nos substratos, de maior fertilidade. Espécies oriundas de ecossistemas inundados cresceram melhor que as oriundas de terra firme. Foi observada nodulação em 30 espécies. Entre as que apresentaram maiores taxas de crescimento, havia tanto espécies nodulíferas como não-nodulíferas, indicando que a fixação biológica de $\mathrm{N}_{2}$ não é o único mecanismo eficiente de absorção de nitrogênio em legumi nosas tropicais. As espécies que apresentaram as maiores taxas de crescimento foram: Enterolobium maximum, Swartzia polyphylla e Vatairea guianensis.
\end{abstract}

Termos de indexação: Fixação biológica de $\mathbf{N}_{2}$, leguminosas florestais, rizóbio, substrato.

\section{SUMMARY: NURSERY GROWTH AND NODULATION OF FORTY-NINE WOODY LEGUME SPECIES NATIVE FROM AMAZONIA}

Although periodically flooded ecosystems represent $25 \%$ of the total Amazon area, they contribute to $75 \%$ of timber production. Both periodically flooded and upland ecosystems are

\footnotetext{
(1) Trabalho financiado com recursos da FINEP. Recebido para publicação em julho de 1996 e aprovado em outubro de 1997.

(2) Professor do Departamento de Ciência do Solo da Universidade Federal de Lavras, Caixa Postal 37, CEP $37200-000$ Lavras (MG), E-mail: fmoreira@esal.ufla.br. Bolsista do CNPq.
} 


\begin{abstract}
greatly di verse in species bel onging to Legumi nosaefamily. Some of thesespecies arecurrently expl oited, but the economic potential of the vast majority has been overl ooked. The knowledge of the plant growth characteristics of these species under nursery conditions is the first step to understand their biology and establish artificial woodlands in deforested areas. This paper reports data on the initial growth and nodulation of 49 species native from both Amazonian ecosystems. All experiments werecarried out at thel nstituto Nacional dePesquisas da Amazônia, State of Amazonas, Brazil , during 1985 and 1986. Pregerminated seedlings weretransplanted into plastic bags containing five different substrata under nursery conditions. All species developed well and no differences amongst substrata were observed, except for a few species which grew better in higher fertility substrata. Species originating from periodically flooded ecosystems grew better than those from upland ecosystems. Nodulation was observed in only thirty species. Somenon-nodul ating species grew as fast as thenodulating ones, indi cating that biol ogical nitrogen fixation is not theonly efficient mechanism of nitrogen acquisiti on for tropical legume species. Species with maximum growth rate were Enterolobium maximum, Swartzia polyphylla and Vatairea guianensis.
\end{abstract}

Index terms: Biological nitrogen fixation, Leguminosae, rhizobia, forest species, substrate

\section{INTRODUÇÃO}

Os ecossistemas florestais da Amazônia podem ser divididos, primariamente, em ecossistemas de "terra firme"e "periodicamenteinundados". Ambos mostram grande diversidadede espécies da família Leguminosae. As leguminosas podem desempenhar importante papel na recuperação de áreas degradadas ou como componentes desistemas agroflorestais, pois possuem mecanismos eficientes de aquisição de nitrogênio, que incluem a fixação biológica de $N_{2}$ (McKey, 1994; Sprent, 1994).

Apesar deterem potencial econômico desconhecido ou ainda inexplorado, muitas dessas espécies já são exploradas, principal mente com fins madeireiros. No entanto, a expl oração desses recursos é feita de modo predominantemente extrativista, estando os raros plantios restritos, em sua maioria, a áreas experimentais (Fernandes \& Sampaio, 1991; J ansen \& Alencar, 1991; Franco \& Faria, 1995).

Os conhecimentos básicos sobre tecnologia de sementes e comportamento dessas espécies em viveiro, fundamentais para plantios em larga escala, ainda são escassos.

Num trabalho inicial com 51 espécies nativas e introduzidas, Moreira (1995) verificou que algumas leguminosas, tanto nodulíferas como não-nodulíferas, têm crescimento rápido no viveiro, usando, como substrato, o horizonteA de dois sol os representativos da Amazônia.

Dando continuidade a esse trabalho, são apresentadas informações sobre o crescimento e nodulação de 49 espécies adicionais de leguminosas, oriundas de áreas periodicamente inundadas (33) ou de terra firme (16) da Amazônia, utilizando cinco substratos em viveiro. A nodulação das espécies nodulíferas, inoculadas e cultivadas em areias, foi comparada com a conseguida em outros substratos, que possuíam estirpes nativas de rizóbio.

\section{MATERIAL E MÉTODOS}

Material botânico e sementes de 49 espécies arbóreas foram coletados em hábitat natural nos municípios de Manaus e Manacapuru, noArquipélago de Anavilhanas, em área do reservatório de Tucuruí (PA) e no Estado do Acre. Não foi possível a coleta de número el evado de sementes para al gumas espécies, por terem elas seus frutos predados (e.g. Lecointea amazonica) ou terem altura muito elevada, dificultando a col eta defrutos (e.g. Pel togyneprance). Para outras espécies, como Campsiandra comosa, Crudia pubescens, Macrolobium acaciifolium, Pithecellobium arenarium, P. multiflorum, Ormosia macrocalyx e Vatairea guianesis, foram coletadas sementes de diferentes procedências, que foram analisadas, separadamente. Informações sobre os dados de coleta (local e data) e morfologia inicial de plântulas (MIP) detodas as espécies estudadas podem ser obtidas em Silva et al. (1988), e M oreira \& Moreira (1996), exceto de MIP de algumas espécies de terra firme. A identificação das espécies foi feita por comparação com exsicatas do Herbário do Departamento de Botânica do Instituto Nacional de Pesquisas da Amazônia (INPA). A maior parte do material botânico coletado foi incorporado à coleção do herbário, onde recebeu números de registro. $\mathrm{O}$ material botânico não incorporado à coleção do herbário permaneceu com o número de col eta.

Os experimentos foram desenvolvidos no viveiro do Campus do Instituto Nacional de Pesquisas da Amazônia (estrada do V8), em Manaus. As sementes foram colocadas para germinar em caixas com areia lavada e esterilizada. Para as espécies de tegumento duro, como Parkia sp e Ormosia sp, foi necessário um tratamento prévio para quebra de dormência; para isso, foi utilizadoácido sulfúrico concentrado (ou água quente), por 30 minutos. Quando as primeiras fol has definitivas já estavam formadas, repicaram-se as plântulas para sacos de polietileno que continham $2 \mathrm{~kg}$ 
Quadro 1. Altura de mudas de leguminosas arbóreas, oriundas de áreas inundadas periodicamente, em cinco substratos no viveiro, aos cinco meses de idade

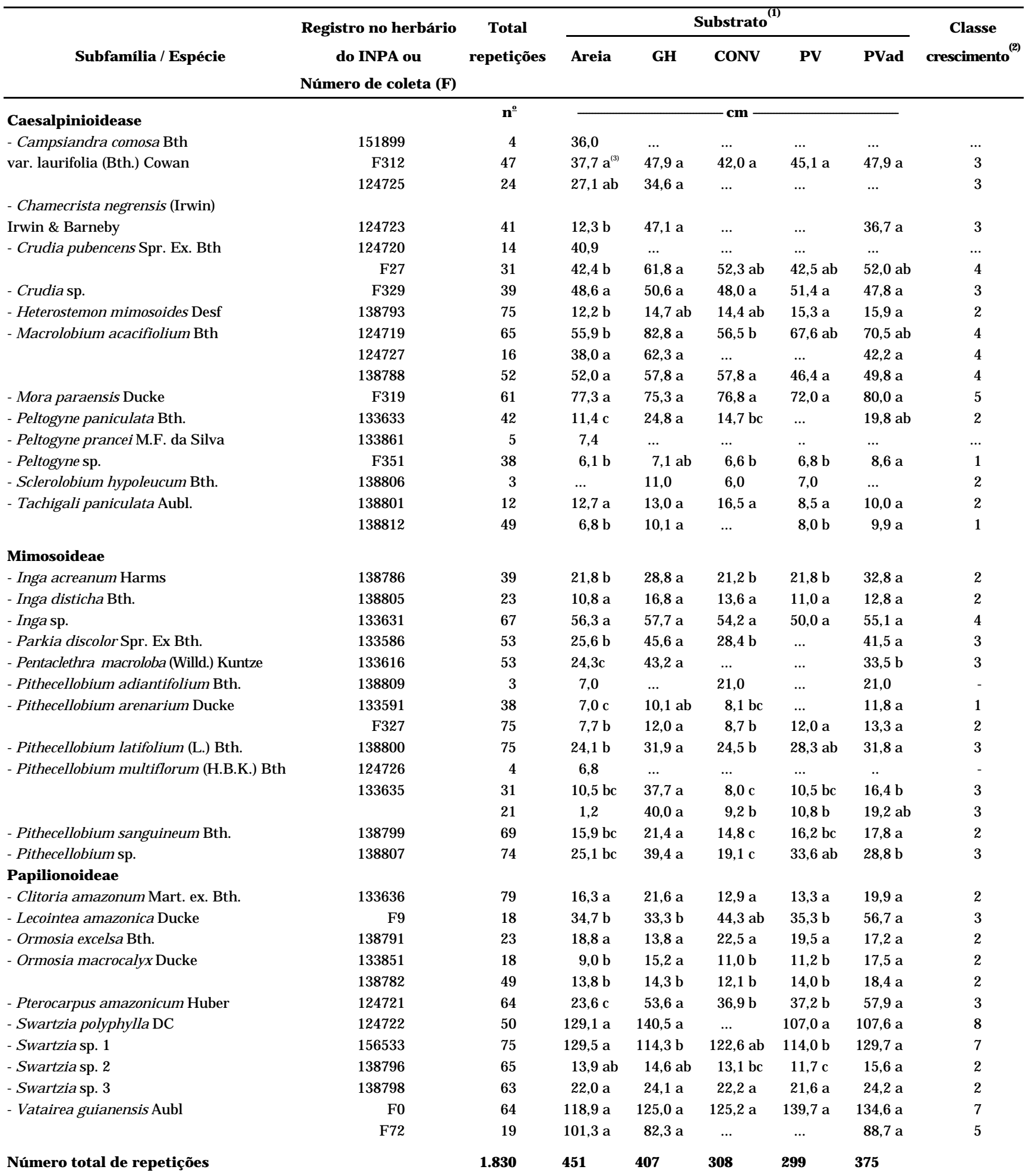

(1)AREIA- areia lavada com inóculo misto de 100 estirpes de rizóbiotadubação (por saco) de: $3 \mathrm{~mL} \mathrm{CaSO}_{4} \mathrm{~mol} \mathrm{~L}^{-1}, 4 \mathrm{~mL}$ de $\mathrm{K}_{2} \mathrm{SO}_{4} \mathrm{~mol} \mathrm{~L}^{-1}$, $2 \mathrm{~mL} \mathrm{Na} \mathrm{HPO}_{4} \mathrm{~mol} \mathrm{~L}^{-1}, 4 \mathrm{~mL} \mathrm{MgSO} \mathrm{mol} \mathrm{L}^{-1} \mathrm{el} \mathrm{mL}$ solução de micronutrientes (por litro: $2,86 \mathrm{~g} \mathrm{H}_{3} \mathrm{BO}_{3} ; 1,81 \mathrm{~g} \mathrm{MnCl}_{2} ; 0,22 \mathrm{~g} \mathrm{ZnSO}_{4}$.7H $\mathrm{O}_{2}$; $0,8 \mathrm{~g} \mathrm{CuSO}_{4} \cdot 5 \mathrm{H}_{2} \mathrm{O} ; 0,02 \mathrm{~g} \mathrm{MoO}_{3} \cdot 2 \mathrm{H}_{2} \mathrm{O}$ e $\left.0,02 \mathrm{~g} \mathrm{CoCl}_{2}\right) ; \mathrm{GH}$ - horizonte A de sol o glei húmico col etado na várzea do Rio Solimões; CONV - substrato convencional de viveiro consistindo de mistura de argila e areia na proporção 3:2 (VN); PV - Horizonte A de podzólico vermel ho-amarel o col etado na Reserva Floresta Ducke (Manaus) e PVad - substrato PV adubado (por saco) com: 3 g e cal cário dol omítico, $0,2 \mathrm{~g}$ de superfosfato simples, 0,2 g de fosfato de rocha (Bauxita do Maranhão) , $4 \mathrm{ml}$ de $\mathrm{K}_{2} \mathrm{SO}_{4} \mathrm{~mol} \mathrm{~L}^{-1}$ e $1 \mathrm{~mL}$ de solução de micronutrientes. (2) classe 1: menor ou igual a $10 \mathrm{~cm}$; classe 2: de 10,1 a $30 \mathrm{~cm}$; classe 3: de 30,1 a $50 \mathrm{~cm}$; classe 4: de 50,1 a 70 cm; classe 5: de 70,1 a $90 \mathrm{~cm}$; classe 6: de 90,1 a $110 \mathrm{~cm}$; classe 7 de 110,1 a $130 \mathrm{~cm}$; e classe 8: de 130,1 a $150 \mathrm{~cm}$. (3)Médias seguidas por letras distintas na mesma linha diferem entre si ao nível de $5 \%$ pelo teste de Duncan. 
dos seguintes substratos: AREIA - areia lavada com inóculo misto de 100 estirpes de rizóbio + adubação (por saco) de: $3 \mathrm{~mL} \mathrm{CaSO}_{4} \mathrm{~mol} \mathrm{~L}^{-1}, 4 \mathrm{~mL}$ de $\mathrm{K}_{2} \mathrm{SO}_{4} \mathrm{~mol} \mathrm{L-1}$, $2 \mathrm{~mL} \mathrm{Na}_{2} \mathrm{HPO}_{4} \mathrm{~mol} \mathrm{~L}^{-1}, 4 \mathrm{~mL} \mathrm{MgSO} \mathrm{mol} \mathrm{L}^{-1}$ e $1 \mathrm{~mL}$ solução de micronutrientes (por litro: 2,86 $\mathrm{g} \mathrm{H}_{3} \mathrm{BO}_{3}$; $1,81 \mathrm{~g} \mathrm{MnCl}_{2} ; 0,22 \mathrm{~g} \mathrm{ZnSO}_{4} 7 \mathrm{H}_{2} \mathrm{O} ; 0,8 \mathrm{~g} \mathrm{CuSO}_{4} .5 \mathrm{H}_{2} \mathrm{O}$; $0,02 \mathrm{~g} \mathrm{MoO}_{3} \cdot 2 \mathrm{H}_{2} \mathrm{O}$ e $0,02 \mathrm{~g} \mathrm{CoCl}_{2}$ ); $\mathrm{GH}$ - horizonte $\mathrm{A}$ de solo glei húmico, coletado na várzea do Rio Solimões; CONV - substrato convencional de viveiro, consistindo de mistura de argila e areia na proporção 3:2 (VN); PV - Horizonte A de podzólico vermel hoamarelo, coletado na Reserva Floresta Ducke (Manaus), e PVad - substrato PV adubado (por saco) com: $3 \mathrm{~g}$ de cal cário dol omítico, 0,2 g de superfosfato simples, 0,2 $\mathrm{g}$ de fosfato de rocha (bauxita do Maranhão), $4 \mathrm{ml}$ de $\mathrm{K}_{2} \mathrm{SO}_{4} \mathrm{~mol} \mathrm{~L}^{-1}$ e $1 \mathrm{~mL}$ de solução de micronutrientes. As características químicas dos substratos GH, CONV e PV são as seguintes: GH $\mathrm{pH}$ em água $=4,9 ; \mathrm{Al}=5 \mathrm{mmol}_{\mathrm{C}} \mathrm{kg}^{-1} ; \mathrm{Ca}+\mathrm{Mg}=$ $136 \mathrm{mmol}_{\mathrm{C}} \mathrm{kg}^{-1} ; \mathrm{K}=5 \mathrm{mg} \mathrm{kg}^{-1} ; \mathrm{P}=75 \mathrm{mg} \mathrm{kg}^{-1} ; \mathrm{CONV}-$ $\mathrm{pH}$ em água $=5,2 ; \mathrm{Al}=1 \mathrm{mmol}_{\mathrm{c}} \mathrm{kg}^{-1} ; \mathrm{Ca}+\mathrm{Mg}=$ $60 \mathrm{mmol}_{\mathrm{C}} \mathrm{kg}^{-1} ; \mathrm{K}=17 \mathrm{mg} \mathrm{kg}^{-1} ; \mathrm{P}=2 \mathrm{mmol}_{\mathrm{C}} \mathrm{kg}^{-1} ; \mathrm{PV}-$ $\mathrm{pH}$ em água $=4,3 ; \mathrm{Al}=14 \mathrm{mmol}_{\mathrm{c}} \mathrm{kg}^{-1} ; \mathrm{Ca}+\mathrm{Mg}=$
$3 \mathrm{mmol}_{\mathrm{C}} \mathrm{kg}^{-1} ; \mathrm{K}=23 \mathrm{mg} \mathrm{kg}^{-1} ; \mathrm{P}=2 \mathrm{mg} \mathrm{kg}^{-1}$, sendo oP determinado pelo Mehlich-1. Foram repicadas três plântulas por saco. A pós a repicagem, as mudas foram col ocadas em viveiro com cobertura de sombrite (50\%), em delineamento experimental inteiramente casualizado. Quinze dias após a repicagem, procedeuse ao desbaste, deixando-se apenas uma planta por saco. Dependendo da disponibilidade de sementes germinadas na espécie, foram feitas de quatroa quinze repetições (sacos com 1 planta), por tratamento (substrato) (Quadros 1 e 2).

O crescimento das mudas foi acompanhado por medidas periódicas de altura. Cinco meses após a emergência, para a maioria das espécies, foram determinados os seguintes parâmetros: diâmetro do colo, peso da parte aérea e das raízes secas, número e peso de nódul os em pelo menos cinco plantas de cada substrato, quando possível. A todas as espécies foi atribuído um valor de classe de crescimento relativo à medida em altura no substratoGH eregistrada aos cinco meses de crescimento, conforme se segue: classe 1: inferior ou igual a $10 \mathrm{~cm}$; classe 2: de 10,1 a $30 \mathrm{~cm}$; classe 3: de 30,1 a $50 \mathrm{~cm}$; classe 4: de 50,1 a $70 \mathrm{~cm}$;

\section{Quadro 2. Altura de mudas de leguminosas arbóreas, oriundas de áreas de terra firme da Amazônia, em cinco substratos no viveiro, aos cinco meses de idade}

\begin{tabular}{|c|c|c|c|c|c|c|c|c|}
\hline \multirow{3}{*}{ Subfamília / Espécie } & \multirow{3}{*}{$\begin{array}{c}\text { Registro no herbário } \\
\text { do INPA ou } \\
\text { Número de coleta (F) }\end{array}$} & \multirow{3}{*}{$\begin{array}{c}\text { Total } \\
\text { repetições }\end{array}$} & \multicolumn{5}{|c|}{ Substrato $^{(1)}$} & \multirow{3}{*}{$\begin{array}{c}\text { Classe } \\
\text { crescimento }^{(2)}\end{array}$} \\
\hline & & & Areia & GH & CONV & PV & PVad & \\
\hline & & & & & & & & \\
\hline Caesalpinioidease & & $\mathrm{n}^{\circ}$ & \multicolumn{5}{|c|}{$\longrightarrow \mathrm{cm} \longrightarrow$} & \\
\hline Copaifera multijuga Hayne & F142 & 56 & $11,4 b^{(3)}$ & $15,7 a$ & $\ldots$ & $15,1 \mathrm{a}$ & $15,9 a$ & 2 \\
\hline Cynometra baunifolia Bth & F249 & 70 & $12,8 \mathrm{~b}$ & $20,1 \mathrm{a}$ & $13,5 b$ & $14,6 b$ & $20,0 \mathrm{a}$ & 2 \\
\hline Macrol obium sp. & F508 & 3 & 14,0 & 24,0 & $\ldots$ & $\ldots$ & 28,0 & 2 \\
\hline \multicolumn{9}{|l|}{ Mimosoideae } \\
\hline Calliandra tenuiflora Bth & F437 & 44 & $6,0 \mathrm{c}$ & $10,3 \mathrm{~b}$ & $9,8 b c$ & $7,4 \mathrm{bc}$ & 14,6 a & 2 \\
\hline Enterol obium maximum Ducke & T8 & 73 & $59,4 b$ & $73,6 a$ & 53,1 bc & $49,9 \mathrm{bc}$ & $44,9 c$ & 5 \\
\hline Inga calantha Ducke & F338 & 72 & $7,8 b$ & $11,0 \mathrm{a}$ & $8,7 b$ & $8,8 b$ & 10,4 a & 2 \\
\hline Inga ingoides (Rich.) Willd. & 151916 & 47 & $9,3 b$ & $12,3 \mathrm{a}$ & $10,3 \mathrm{~b}$ & $13,1 \mathrm{a}$ & $13,3 \mathrm{a}$ & 2 \\
\hline Inga sp. 1 & F517 & 10 & 8,0 & 11,0 & 6,5 & 5,5 & 8,5 & 2 \\
\hline Inga sp. 2 & F518 & 8 & 6,5 & 7,0 & 5,0 & 10,0 & 11,5 & 1 \\
\hline Parkia oppositifolia Bth. & 133615 & 75 & 17,3 a & 19,5 a & 19,3 a & 19,5 a & $19,5 \mathrm{a}$ & 2 \\
\hline Pithecel lobium caul iflorum (Willd.) Bth. & F522 & 75 & $12,7 \mathrm{~b}$ & 14,5 a & $12,3 \mathrm{~b}$ & 15,5 a & $16,0 \mathrm{a}$ & 2 \\
\hline Stryphnodendron sp. & $\mathrm{T7}$ & 51 & $6,0 \mathrm{c}$ & $13,3 \mathrm{a}$ & $12,1 \mathrm{ab}$ & $12,5 \mathrm{ab}$ & $10,3 \mathrm{bc}$ & 2 \\
\hline \multicolumn{9}{|l|}{ Papilionoideae } \\
\hline Andira inermis (Sw.) H.B.K.) & 151920 & 75 & $32,5 \mathrm{c}$ & $36,7 a b$ & 35,1 bc & $35,3 a b c$ & 38,6 a & 3 \\
\hline Andira micrantha Ducke & 133872 & 27 & 25,1 a & 24,3 a & $\ldots$ & $\ldots$ & $\ldots$ & 2 \\
\hline Dalbergia sp. & F519 & 6 & 13,0 & 11,0 & 9,0 & 9,0 & 11,0 & 2 \\
\hline Platymiscium duckei Huber & 139629 & 46 & $12,2 \mathrm{~b}$ & $16,5 \mathrm{a}$ & 8,8 bc & $8,3 c$ & 16,7 a & 2 \\
\hline № total de repetições & & 738 & 153 & 170 & 129 & 144 & 142 & \\
\hline
\end{tabular}

(1)AREIA - areia lavada com inóculo misto de 100 estirpes de rizóbio + adubação (por saco) de: $3 \mathrm{~mL} \mathrm{CaSO} \mathrm{mol} \mathrm{L}^{-1}, 4 \mathrm{~mL}$ de $\mathrm{K}_{2} \mathrm{SO}_{4}$ mol L-1, $2 \mathrm{~mL} \mathrm{Na}_{2} \mathrm{HPO}_{4} \mathrm{~mol} \mathrm{~L}^{-1}, 4 \mathrm{~mL} \mathrm{MgSO}_{4} \mathrm{~mol} \mathrm{~L}^{-1}$ e $1 \mathrm{~mL}$ solução de micronutrientes (por litro: $2,86 \mathrm{~g} \mathrm{H}_{3} \mathrm{BO}_{3} ; 1,81 \mathrm{~g} \mathrm{MnCl}_{2} ; 0,22 \mathrm{~g}$ $\mathrm{ZnSO}_{4} .7 \mathrm{H}_{2} \mathrm{O} ; 0,8 \mathrm{~g} \mathrm{CuSO}_{4} .5 \mathrm{H}_{2} \mathrm{O} ; 0,02 \mathrm{~g} \mathrm{MoO}_{3} .2 \mathrm{H}_{2} \mathrm{O}$ e $0,02 \mathrm{~g} \mathrm{CoCl}_{2}$ ); $\mathrm{GH}$ - horizonte A de solo glei húmico coletado na várzea do Rio Solimões; CONV - substrato convencional de viveiro consistindo de mistura de argila e areia na proporção 3:2 (VN); PV - H orizonte A de podzól ico vermel ho-amarel o col etado na Reserva Floresta Ducke (Manaus) e PVad - substrato PV adubado (por saco) com: $3 \mathrm{~g}$ de cal cário dolomítico, 0,2 g de superfosfato simples, 0,2 g de fosfato de rocha (Bauxita do Maranhão) , $4 \mathrm{ml}$ de $\mathrm{K}_{2} \mathrm{SO}_{4} \mathrm{~mol} \mathrm{~L}^{-1}$ e $1 \mathrm{~mL}$ de solução de micronutrientes. (2) classe 1: menor ou igual a $10 \mathrm{~cm}$; classe 2: de 10,1 a $30 \mathrm{~cm}$; classe 3: de 30,1 a $50 \mathrm{~cm}$; classe 4: de 50,1 a 70 cm; e classe 5: de 70,1 a $90 \mathrm{~cm}$. (3)Médias seguidas por letras distintas na mesma linha diferem entre si ao nível de 5\% pelo teste de Duncan. 
classe 5: de 70,1 a $90 \mathrm{~cm}$; classe 6: de 90,1 a $110 \mathrm{~cm}$; classe 7 de 110,1 a 130 cm; edasse 8: de 130,1 a 150 cm.

De cada espécie nodulífera, selecionaram-se nódul os para medida da atividade da nitrogenase pelo método deredução de acetileno (ARA) (Dil worth, 1966) e isolamento de rizóbio. O meio utilizado foi o YMA (Vincent, 1970).

Os dados de crescimento das espécies foram submetidos à análise de variância eao teste de médias pelo programa estatístico SANEST (Sarriés et al., 1992).

\section{RESULTADOS E DISCUSSÃO}

A mai oria das espécies apresentou crescimento em altura semelhante nos cinco substratos. Algumas espécies, como Chamaecrista negrensis, Parkia discolor, Pentachletra macrol oba, Pithecel lobium multifl orum e Pterocarpus amazoni cum, oriundas de áreas inundadas, e Cynometra bauhiniifolia, Enterol obium maximum e Platymiscium duckei, oriundas de terra firme, cresceram melhor nos substratos de maior fertilidade: glei húmico $(\mathrm{GH})$ e podzól ico vermel ho-amarel o adubado (PVad) (Quadros 1 e 2). Outras características de crescimento, como peso da parte aérea seca e peso da raiz seca, também seguiram a mesma tendência do parâmetro altura (Quadros 3 e 4).

Segundo Aung (1974), a relação raiz/parte aérea varia com a espécie de planta, idade, estádio de desenvolvimento e tipo de ambiente, e o aumento da fertilidade do solo diminui a relação, o que foi observado neste trabalho. Os valores R/PA entre as diferentes espécies tiveram ampla variação, considerando o mesmo substrato. A R/PA média de todas as espécies nos substratos AREIA, GH, CONV, PV e PVad foram de: 0,$50 ; 0,35 ; 0,51 ; 0,50$ e 0,40 , para as oriundas de área inundada, e de 0,$45 ; 0,29 ; 0,41$; 0,34 e 0,32 , para as oriundas de terra firme, respectivamente. Observou-seque os menores val ores foram obtidos nos substratos de mai or fertilidade: $\mathrm{GH}$ e PVad. Além disso, as espécies de terra firme apresentaram relação menor que as de áreas inundadas, o que indica diferenças fisiológicas relacionadas com a procedência dessas espécies.

As Caesal pinioi deae de áreas inundadas e de terra firmeapresentaram, respectivamente, classes de crescimento de 1 a 5 e de 2, as Mimosoideae, de 1 a 4 e de 1 a 5 , enquanto as Papilionoideae apresentaram de 2 a 8 e 2 a 3 (Quadros 1 e 2; Figuras 1 e 2 ). As espécies incluídas na maior classe de crescimento, oriundas de áreas inundadas, em cada subfamília, foram, respectivamente: Mora paraensis (Caesal pinioideae); I nga sp (Mimosoi deae), Swartzia polyphylla eVatairea guianensis (Papilionoideae), todas com morfologia inicial de plântulas do tipo hipógeo. Enterolobium maxi mum (Mimosoi deae - epígea) foi a única espécie oriunda de terra firme que foi enquadrada na classe de crescimento maior que 4. As espécies hipógeas se situaram nas classes mais al tas de crescimento (entre
2 e 8). As espécies epígeas, com exceção de E. maximum, permaneceram na classe de crescimento menor que 3. As espécies situadas na maior classe de crescimento $(6,7$ e 8 ) eram Papilionoi deae hi pógeas. A quantidade de reservas nutricionais nas sementes pode, pelo menos parcialmente, explicar as taxas de crescimento inicial. Espécies com maiores taxas de crescimento, como Swartzia polyphylla e Vatairea guianensis, tinham as maiores sementes. Houve correlação significativa entre crescimento em altura e comprimento das sementes para as espécies estudadas, de cada subfamília, na maioria dos substratos (Quadro 5), exceto para GH (espécies de terra firme e Mimosoideae inundadas) e CONV (Mimosoideae inundadas), o que, pel o menos para GH, pode ser explicado pela mai or influência da fertilidade no crescimento das mudas. Em trabalho anterior (Moreira, 1995), nãofoi encontrada correl ação positiva entre crescimento e tamanho de sementes, provavelmente porque entre as leguminosas estudadas havia espécies exóticas cultivadas, como Leucaena spp.

A maioria das espécies estudadas foi coletada em florestas virgens enão foi ainda cultivada atésua fase adulta. Porém, para várias espécies, foi relatado o porteal cançado em seu habitat natural (Ducke, 1949). De modo geral, encontrou-se uma relação positiva entre a taxa de crescimento das espécies em viveiro e o porteal cançado em condições naturais. Por exemplo, Enterolobium maximum é descrita como "uma das maiores árvores da mata virgem amazônica" e M ora paraensis e Vatairea guianensis como "espécies de grande porte das áreas inundadas". Outras são descritas como árvores pequenas (e.g. Calliandra tenuifl ora, Heterostemon mi mosoides) a medianas (e.g. Cynometra bauhinifolia e Campsiandra comosa). As exceções foram verificadas para as espécies: Copai fera multijuga, Parkia oppositifolia, Andira spp., Peltogyne prance e Peltogyne paniculata, geralmente descritas como de grande porte, mas que foram alocadas nas classes de crescimento 2 ou 3 no viveiro.

Tanto espécies nodulíferas como não-nodulíferas foram enquadradas nas classes de crescimento entre 1 e 8, confirmando que, além da fixação biológica de $\mathrm{N}_{2}$, existem outros mecanismos eficientes de absor ção de nitrogênio em legumi nosas (Sprent, 1994; McK ey, 1994), pois nenhum dos substratos recebeu adubação nitrogenada. Trinta das 49 espécies nodularam no viveiro (Quadros 6 e 7). Nos substratos AREIA, GH, CONV, PV e PVad, respectivamente, 97, 91, 93, 76 e $73 \%$ dessas espécies nodularam. Tais resultados confirmam otrabal ho anterior de M oreira (1995), com outras 48 espécies arbóreas, que apresentaram maior nodulação no substrato $\mathrm{GH}$ em relação ao PVad. O número e o peso de nódulos foram, de modo geral, maiores no substratoAREIA, provavel menteem razão da maior lixiviação de $\mathrm{N}$ e/ou do el evado número de células de rizóbio introduzidas no substrato via inoculação. No entanto, várias espécies tiveram, nos demais substratos, nodulação abundante e/ou semel hante ao observado na AREI A, demonstrandoa existência de estirpes nativas capazes de infectar plantas. Por outro lado, espécies que nodularam no 
Quadro 3. Crescimento inicial de leguminosas arbóreas, oriundas de áreas periodicamente inundadas, em cinco substratos no viveiro

\begin{tabular}{|c|c|c|c|c|c|c|c|c|c|c|c|c|c|c|c|}
\hline \multirow[b]{2}{*}{ Família/Espécie } & \multicolumn{15}{|c|}{ Substrato $^{(1)}$} \\
\hline & Areia & GH & Conv & PV & PVad & Areia & GH & Conv & PV & PVad & Areia & GH & Conv & PV & PVad \\
\hline & & Peso par & te aérea & seca & & & —Peso & raiz seca & $a(g)$ & & & - Rela & ação R/ & PA & \\
\hline \multicolumn{16}{|l|}{ Caesalpinioideae } \\
\hline Campsiandra comosa Bth. & $3,14 b^{(2)}$ & $7,23 a$ & $3,24 b$ & $5,48 a b$ & $4,37 a b$ & $0,84 b$ & $1,79 a$ & $1,17 a b$ & $1,63 \mathrm{ab}$ & $1,23 a b$ & 0,26 & 0,25 & 0,36 & 0,30 & 0,28 \\
\hline Crudia pubescens Spr. E & $8,39 a$ & $9,53 a$ & $7,24 a$ & $7,30 \mathrm{a}$ & $7,57 a$ & $2,18 a$ & $3,04 a$ & $2,07 a$ & $2,09 a$ & $1,94 a$ & 0,26 &, 32 & 28 & 0,29 & 0,26 \\
\hline Heterostemon mimosoi des Desf. & $0,65 b$ & $0,93 \mathrm{ab}$ & $0,89 a b$ & $1,01 \mathrm{ab}$ & $1,28 a$ & $0,49 a$ & $0,47 a$ & $0,57 a$ & $0,66 a$ &, $42 a$ & 0,76 &, 50 & 64 & 0,65 & 50,33 \\
\hline Macrolobium & $4,00 a$ & $7,24 a$ & $5,82 a$ & $3,36 a$ & $4,28 a$ & $1,82 a$ & $2,40 a$ & $2,46 a$ & $1,60 a$ & $1,74 a$ & 0,46 & ,33 & 43 & 0,48 & 30,41 \\
\hline Mora paraensis Ducke & $27,60 a$ & $32,40 a$ & $32,64 a$ & $39,00 a$ & $44,39 a$ & $11,23 a$ & $13,68 a$ & $16,82 \mathrm{a}$ & $12,78 \mathrm{a}$ & $11,28 a$ & 0,41 & ,43 & 51 & 0,33 & 30,25 \\
\hline Peltogynepanicul & $0,29 b$ & $3,62 a$ & $0,74 b$ & $\ldots$ & $1,53 b$ & $0,28 a$ & $1,12 \mathrm{a}$ & $0,43 a$ & $\ldots$ & $93 a$ & ,96 & 31 & 58 & $\ldots$ & 0,61 \\
\hline Peltogynesp. & $0,25 b$ & $0,62 a$ & $0,30 \mathrm{~b}$ & $0,40 \mathrm{~b}$ & $0,44 a b$ & $0,09 a b$ & $0,10 a$ & La & $0,05 b$ & $06 \mathrm{ab}$ & 0,36 & 16 & 33 & 0,12 & $2 \quad 0,14$ \\
\hline Tachigali pania & 0,69 & 0,84 & 1,29 & 0,45 & 0,30 & & & & 0,06 & 05 &, 17 & 0,01 & , 24 & 0,13 & 30,17 \\
\hline \multicolumn{16}{|l|}{ Mimosoideae } \\
\hline Inga acreanum $\mathrm{Ha}$ & $42 \mathrm{~b}$ & $6,35 a$ & $1,61 \mathrm{~b}$ & $2,41 \mathrm{~b}$ & $6,83 a$ & $0,86 \mathrm{~b}$ & $2,60 a$ & $0,63 b$ & $1,25 \mathrm{~b}$ & $2,98 a$ & 0,36 & 0,41 & 0,39 & 0,52 & 20,44 \\
\hline I. disticha & $0,50 a$ & $1,40 a$ & $0,70 a$ & $0,60 a$ & $0,56 a$ & $0,26 a$ & $0,69 a$ & $0,58 a$ & $0,57 a$ & $0,40 a$ & 0,52 & 0,49 & ,83 & 0,95 & 50,71 \\
\hline Inga sp. & $4,90 \mathrm{~b}$ & $9,28 a$ & $5,60 \mathrm{ab}$ & $6,83 \mathrm{ab}$ & $9,44 a$ & $2,15 a$ & $3,09 a$ & $2,97 a$ & $3,08 a$ & $3,27 a$ & 0,44 & 0,33 & 0,53 & 0,45 & $5 \quad 0,35$ \\
\hline Parkia discol or spr. Ex Bth. & $0,71 b$ & $4,15 a$ & $1,34 b$ & $\ldots$ & $1,66 \mathrm{~b}$ & $0,4 b$ & $1,40 a$ & $0,96 a b$ & $\ldots$ & $0,89 a b$ & 0,56 & 0,34 & 0,72 & ... & 0,54 \\
\hline \multirow[t]{2}{*}{ P. arenarim Ducke } & $0,60 \mathrm{~b}$ & $1,75 a b$ & $1,09 \mathrm{~b}$ & $\ldots$ & $3,07 a$ & $0,24 a$ & $0,50 a$ & $0,42 a$ & $\ldots$ & $0,64 a$ & 0,4 & 0,28 & ,38 & ... & 0,21 \\
\hline & $0,40 c$ & $1,66 a$ & $0,53 b c$ & $1,11 \mathrm{ab}$ & $1,35 a$ & $0,14 b$ & $0,56 a$ & $0,15 b$ & $0,35 a b$ & $0,34 a b$ & 0,35 & 0,34 & 0,28 & 0,31 & 0,25 \\
\hline P. latifol & $3,28 a$ & $4,77 a$ & $2,34 a$ & $5,74 a$ & $4,82 a$ & $2,65 a b$ & $2,38 a b$ & $1,13 b$ & $3,17 a$ & $2,20 \mathrm{ab}$ & 0,81 & 0,50 & 0,48 & 0,55 & $5 \quad 0,46$ \\
\hline \multirow[t]{2}{*}{ P. multiflorum (H.B.K.) Bth. } & $0,36 \mathrm{~b}$ & $8,19 a$ & $0,35 b$ & $0,37 \mathrm{~b}$ & $1,66 \mathrm{~b}$ & $0,37 \mathrm{~b}$ & $0,73 a$ & $0,25 b$ & $0,29 b$ & $1,36 \mathrm{~b}$ & 1,03 & 0,09 & 0,71 & 0,78 & 30,82 \\
\hline & $\ldots$ & $3,70 a$ & $0,21 b$ & $0,30 \mathrm{~b}$ & $2,45 a$ & $\ldots$ & $3,64 a$ & $0,16 b$ & $0,27 b$ & $2,37 a$ & - & 0,98 & 0,76 & 0,9 & 0,97 \\
\hline P. sa & $0,91 b$ & $1,98 \mathrm{ab}$ & $0,97 b$ & $1,64 a b$ & $2,35 a$ & $0,44 a$ & $0,49 a$ & $0,56 a$ & $0,57 a$ & $0,69 a$ & 0,48 & 0,25 & 0,58 & 0,35 & $5 \quad 0,29$ \\
\hline Pithecel lobium sp. & $2,02 b$ & $9,33 a$ & $1,73 b$ & $1,70 \mathrm{~b}$ & $3,57 b$ & $0,70 \mathrm{~b}$ & $3,11 a$ & $0,74 b$ & $0,74 b$ & $1,14 \mathrm{~b}$ & 0,35 & 0,33 & 0,43 & 0,44 & 0,32 \\
\hline \multicolumn{16}{|l|}{ Papilionoidear } \\
\hline & $1,25 a$ & $3,87 a$ & $36 a$ & $0,83 a$ & $1,60 a$ & $0,65 a b$ & $1,80 a$ & $0,44 b$ & $0,86 a b$ & $1,17 a b$ & 0,52 & 0,46 & 1,22 & 1,04 & 0,73 \\
\hline Ormo & $1,22 \mathrm{a}$ & $0,91 a$ & $2,02 a$ & $1,85 a$ & $1,16 a$ & $0,44 a$ & $0,21 a$ & $0,68 a$ & $0,59 a$ & $0,31 \mathrm{a}$ & 0,36 & 0,23 & 0,34 & 0,32 & 0,27 \\
\hline O. macrocalyx D & $1,92 a$ & $2,22 a$ & $2,02 a$ & $1,42 a$ & $2,60 a$ & $0,80 a$ & $0,77 a$ & $0,81 a$ & $0,69 a$ & $0,66 a$ & 0,42 & 0,35 & 0,40 & 0,48 & 30,25 \\
\hline Swartzia sp. 3 & $1,34 b c$ & $3,40 a$ & $2,66 a b$ & $2,26 a b$ & $0,72 c$ & $1,18 a b$ & $1,52 a$ & $0,98 a b$ & $0,84 a b$ & $0,28 b$ & 0,88 &, 45 & 0,37 & 0,37 & $7 \quad 0,39$ \\
\hline Swa & $28,0 a b$ & $16,6 \mathrm{ab}$ & $32,84 a$ & $29,44 a$ & $16,56 \mathrm{~b}$ & $8,10 a$ & $4,13 b$ & $9,83 a$ & $8,45 a$ & $4,40 \mathrm{~b}$ & 0,29 &, 25 & 0,30 & 0,29 & 9,26 \\
\hline Swartzia sp. 2 & $0,89 \mathrm{~b}$ & $1,80 a$ & $1,38 \mathrm{ab}$ & $2,04 a$ & $0,90 \mathrm{~b}$ & $0,64 b c$ & $1,06 a b$ & $1,24 a$ & $1,32 \mathrm{a}$ & $0,32 \mathrm{c}$ & 0,72 & 0,59 & 0,90 & 0,65 & $5 \quad 0,36$ \\
\hline
\end{tabular}

(1)AREIA - areia lavada com inóculo misto de 100 estirpes de rizóbio + adubação (por saco) de: $3 \mathrm{~mL} \mathrm{CaSO} \mathrm{mol} \mathrm{L}^{-1}, 4 \mathrm{~mL}$ de $\mathrm{K}_{2} \mathrm{SO}_{4}$ mol L-1, $2 \mathrm{~mL} \mathrm{Na}_{2} \mathrm{HPO}_{4} \mathrm{~mol} \mathrm{~L}^{-1}, 4 \mathrm{~mL} \mathrm{MgSO} \mathrm{mol} \mathrm{L}^{-1} \mathrm{e} 1 \mathrm{~mL}$ solução de micronutrientes (por litro: $2,86 \mathrm{~g} \mathrm{H}_{3} \mathrm{BO}_{3} ; 1,81 \mathrm{~g} \mathrm{MnCl}_{2} ; 0,22 \mathrm{~g}$ $\mathrm{ZnSO}_{4} \cdot 7 \mathrm{H}_{2} \mathrm{O} ; 0,8 \mathrm{~g} \mathrm{CuSO}_{4} \cdot 5 \mathrm{H}_{2} \mathrm{O} ; 0,02 \mathrm{~g} \mathrm{MoO}_{3} \cdot 2 \mathrm{H}_{2} \mathrm{O}$ e $0,02 \mathrm{~g} \mathrm{CoCl}_{2}$ ); $\mathrm{GH}$ - horizonte A de solo glei húmico col etado na várzea do Rio Solimões; CONV - substrato convencional de viveiro consistindo de mistura de argila e areia na proporção 3:2 (VN); PV - HorizonteA de podzólico vermelho-amarelo coletado na Reserva Floresta Ducke (Manaus) e PVad - substrato PV adubado (por saco) com: $3 \mathrm{~g}$ de calcário dolomítico, 0,2 g de superfosfato simples, 0,2 g de fosfato de rocha (Bauxita do Maranhão), $4 \mathrm{ml} \mathrm{de} \mathrm{K}_{2} \mathrm{SO}_{4} \mathrm{~mol} \mathrm{~L}^{-1}$ e $1 \mathrm{~mL}$ de solução de micronutrientes. (2)Médias de 5 plantas seguidas por letras distintas numa mesma linha diferem entre si ao nível de $5 \%$ pelo teste de Duncan.

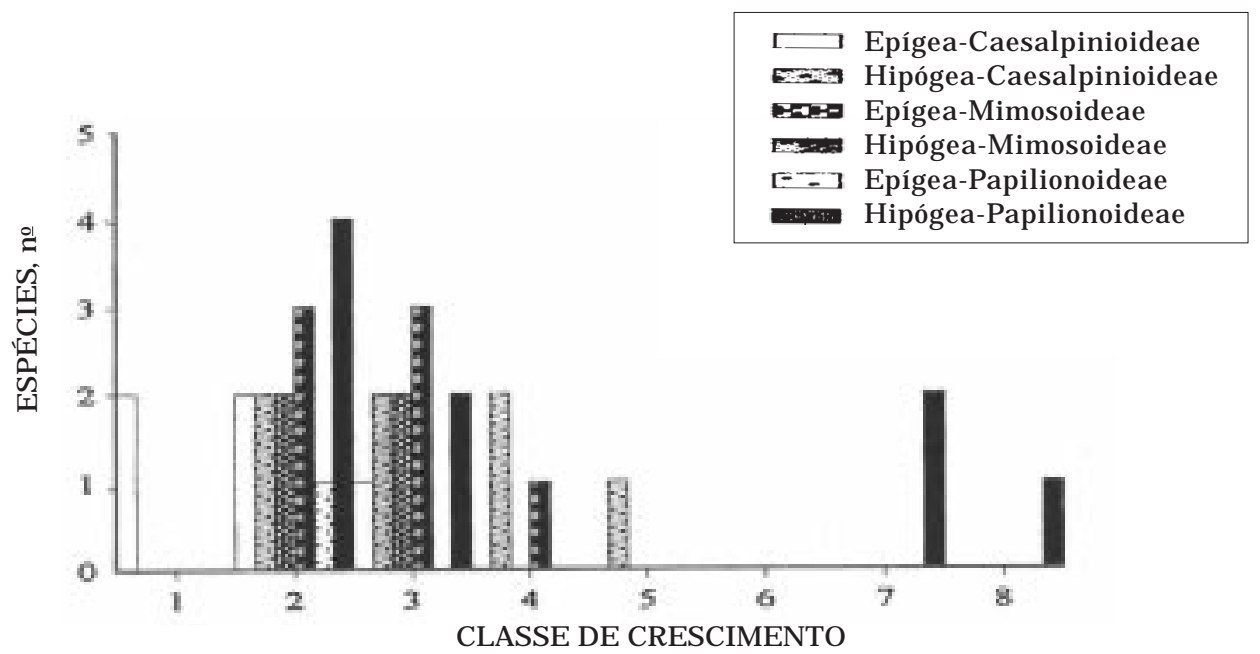

Figura 1. Número de espécies epígeas e hipógeas, oriundas de áreas inundadas, por classe de crescimento de mudas. Classe 1: inferior ou igual a 10 cm; Classe 2: de 10,1 a $30 \mathrm{~cm}$; Classe 3: de 30,1 a 50 cm; Classe 4: de 50,1 a 70 cm; Classe 5: de 70,1 a 90 cm; Classe 6: de 90,1 a 100 cm; Classe 7: de 110,1 a 130 cm; e Classe 8: de 130,1 a $150 \mathrm{~cm}$. 
Quadro 4. Crescimento inicial de leguminosas arbóreas, oriundas deáreas de terra firme, em cinco substratos no viveiro

\begin{tabular}{|c|c|c|c|c|c|c|c|c|c|c|c|c|c|c|c|}
\hline \multirow[b]{2}{*}{ Subfamília/Espécie } & \multicolumn{15}{|c|}{ Substrato $^{(1)}$} \\
\hline & Areia & GH & Conv & PV & PVad & Areia & GH & Conv & PV & PVad & Areia & GH & Conv & PV & PVad \\
\hline & $-F$ & Peso part & e aérea & seca $(g)$ & - & $\longrightarrow$ & —Peso & raiz secá & $a(g)-$ & - & & - Rela & ação R/ & PA & - \\
\hline \multicolumn{16}{|l|}{ Caesalpinioideae } \\
\hline Cynometra bauhiniifolia Bth. & $0,62 b$ & $1,63 a$ & $0,67 b$ & $0,92 b$ & $1,76 a$ & $0,62 b$ & $1,12 \mathrm{a}$ & $0,70 \mathrm{~b}$ & $0,60 \mathrm{~b}$ & $1,12 \mathrm{a}$ & 1,0 & 0,67 & 1,04 & 0,65 & 0,64 \\
\hline \multicolumn{16}{|l|}{ Mimosoideae } \\
\hline Calliandra tenuiflora Bth. & $0,43 b$ & $0,92 b$ & $0,67 b$ & $0,43 b$ & $1,65 a$ & $0,12 b$ & $0,24 b$ & $0,20 \mathrm{~b}$ & $0,19 b$ & $0,64 a$ & 0,28 & 0,26 & 0,30 & 0,44 & 0,39 \\
\hline Enterolobium maximum Ducke & $13,50 \mathrm{~b}$ & $29,0 a$ & $7,28 b$ & $4,64 b$ & $3,86 b$ & $3,92 a b$ & $6,64 a$ & $1,15 b$ & $0,90 \mathrm{~b}$ & $1,23 b$ & 0,24 & 0,23 & 0,16 & 0,19 & 0,32 \\
\hline Inga calantha Ducke & $0,43 d$ & $1,29 a$ & $0,64 d$ & $0,93 b$ & $0,79 b c$ & $0,12 c$ & $0,28 a$ & $0,19 a b$ & $0,27 a b$ & $0,16 b c$ & 0,28 & 0,22 & 0,30 & 0,29 & 0,20 \\
\hline Inga ingoi des (Rich.) Willd & $0,42 b$ & $1,17 \mathrm{a}$ & $0,63 b$ & $0,74 b$ & $0,73 b$ & $0,14 a$ & $0,27 a$ & $0,15 a$ & $0,26 a$ & $0,13 a$ & 0,33 & 0,23 & 0,24 & 0,35 & 0,18 \\
\hline Inga sp. 1 & 0,53 & 0,55 & 0,12 & 0,38 & 0,72 & 0,21 & 0,06 & 0,03 & 0,02 & 0,12 & 0,40 & 0,11 & 0,25 & 0,05 & 0,17 \\
\hline Inga sp. 2 & 0,12 & $\ldots$ & 0,12 & $\ldots$ & 0,86 & 0,09 & $\ldots$ & 0,08 & $\ldots$ & 0,16 & 0,75 & $\ldots$ & 0,67 & $\ldots$ & 0,19 \\
\hline Parkia oppositifolia Bth. & $1,33 a$ & $1,67 a$ & $1,10 a$ & $1,31 \mathrm{a}$ & $1,16 a$ & $0,57 a$ & $0,32 a$ & $0,44 a$ & $0,35 a$ & $0,36 a$ & 0,43 & 0,19 & 0,4 & 0,27 & 0,31 \\
\hline Pithecellobiumcauliflorum (Wiild) Bth. & $0,92 b$ & $1,14 a b$ & $0,92 b$ & $1,30 a$ & $1,07 \mathrm{ab}$ & $0,54 a$ & $0,43 a$ & $0,40 a$ & $0,48 a$ & $0,49 a$ & 0,59 & 0,38 & 0,43 & 0,37 & 0,46 \\
\hline Stryphnodendron sp. & $0,09 b$ & $4,74 a$ & $3,09 a b$ & $1,22 \mathrm{~b}$ & $4,85 a$ & $0,013 b$ & $0,79 a b$ & $0,60 a b$ & $0,22 b$ & $1,0 a$ & 0,14 & 0,17 & 0,19 & 0,18 & 0,21 \\
\hline \multicolumn{16}{|l|}{ Papilionoideae } \\
\hline Andira inermis (Sw.) H.B.K. & $2,73 a$ & $2,74 a$ & $2,64 a$ & $2,54 a$ & $3,16 a$ & $1,06 a b$ & $0,79 b$ & $1,35 a b$ & $0,94 a b$ & $1,48 a$ & 0,39 & 0,29 & 0,51 & 0,37 & 0,47 \\
\hline Dal bergia sp. & 0,27 & $\ldots$ & $\ldots$ & $\ldots$ & $\ldots$ & 0,18 & $\ldots$ & $\ldots$ & $\ldots$ & $\ldots$ & 0,67 & $\ldots$ & $\ldots$ & $\ldots$ & $\ldots$ \\
\hline Platymiscium ducke Huber & $1,31 b$ & $4,13 a$ & $0,97 b$ & $0,71 b$ & $2,04 a b$ & $0,46 b$ & $1,75 a$ & $0,44 b$ & $0,38 b$ & $0,81 b$ & 0,35 & 0,42 & 0,45 & 0,54 & 0,40 \\
\hline
\end{tabular}

(1)AREIA - areia lavada com inóculo misto de 100 estirpes de rizóbio + adubação (por saco) de: $3 \mathrm{~mL} \mathrm{CaSO}_{4} \mathrm{~mol} \mathrm{~L}^{-1}, 4 \mathrm{~mL}$ de $\mathrm{K}_{2} \mathrm{SO}_{4}$ mol L-1, $2 \mathrm{~mL} \mathrm{Na}_{2} \mathrm{HPO}_{4}$ mol L-1, $4 \mathrm{~mL} \mathrm{MgSO}$ mol L-1 e $1 \mathrm{~mL}$ solução de micronutrientes (por litro: $2,86 \mathrm{~g} \mathrm{H}_{3} \mathrm{BO}_{3} ; 1,81 \mathrm{~g} \mathrm{MnCl}_{2} ; 0,22 \mathrm{~g}^{-1}$ $\mathrm{ZnSO}_{4} \cdot 7 \mathrm{H}_{2} \mathrm{O} ; 0,8 \mathrm{~g} \mathrm{CuSO}_{4} \cdot 5 \mathrm{H}_{2} \mathrm{O} ; 0,02 \mathrm{~g} \mathrm{MoO}_{3} \cdot 2 \mathrm{H}_{2} \mathrm{O}$ e $0,02 \mathrm{~g} \mathrm{CoCl}_{2}$ ); GH - horizonte A de solo glei húmico coletado na várzea do Rio Solimões; CONV - substrato convencional de viveiro consistindo de mistura de argila e areia na proporção 3:2 (VN); PV - H orizonte A de podzólico vermelho-amarelo coletado na Reserva Floresta Ducke (Manaus) e PVad - substrato PV adubado (por saco) com: 3 g de

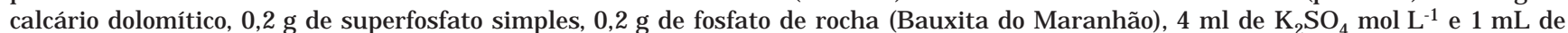
solução de micronutrientes. (2)Médias (de 5 plantas) seguidas por letras distintas numa mesma linha diferem entre si ao nível de $5 \%$ pelo teste de Duncan.

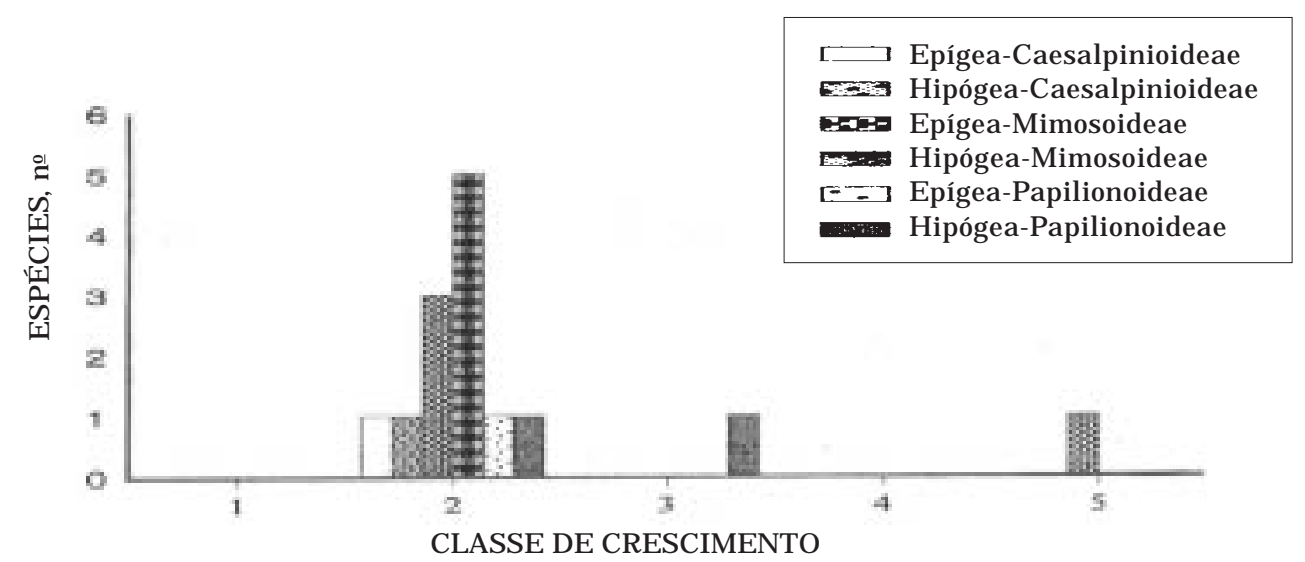

Figura 2. Número de espécies epígeas e hi pógeas, ori undas deáreas de terra firme, por classe de crescimento de mudas. Classe 1: inferior ou igual a 10 cm; Classe 2: de 10,1 a 30 cm; Classe 3: de 30,1 a 50 cm; Classe 4: de 50,1 a 70 cm; Classe 5: de 70,1 a $90 \mathrm{~cm}$.

substratoAREIA, mas não nodularam em um ou mais dos demais substratos, demonstraram que esses substratos não possuíam rizóbio compatível com essas espécies, ou apresentavam fatores limitantes à nodulação. Por este motivo, dependendo da espécie, estudos posteriores devem enfocar as necessidades de correção do solo e/ou da prática de inoculação. Embora não tenha havido uma correlação positiva entre classe de crescimento e nodul ação detodas as espécies, Swartzia polyphylla foi a espécieque apresentou a mai or taxa de crescimento eo mai or peso de nódul os em todos os substratos. A maioria das espécies revel ou nódulos ativos (ARA) em todos os substratos, ea maior parte das estirpes isoladas eram de Bradyrhizobi um sp. Características morfológicas e bioquímicas dessas estirpes podem ser encontradas em M oreira (1991) e Moreira et al. (1993). 
Quadro 5. Coeficientes de correlação entre crescimento em altura e tamanho da semente (comprimento) de 16 espécies de leguminosas arbóreas, oriundas de terra firme (TF), e de 33 espécies, oriundas de áreas inundadas (I), pertencentes às subfamílias Caesalpinioideae (C), Mimosoideae (M) e Papilionoideae (P)

\begin{tabular}{|c|c|c|c|c|c|c|}
\hline \multirow{2}{*}{\multicolumn{2}{|c|}{$\begin{array}{l}\text { Origem das } \\
\text { espécies }\end{array}$}} & \multicolumn{5}{|c|}{ Substrato $^{(1)}$} \\
\hline & & \multirow{2}{*}{$\begin{array}{l}\text { Areia } \\
0,63^{*}\end{array}$} & \multirow{2}{*}{$\frac{\text { G H }}{0,52}$} & \multirow{2}{*}{$\frac{\text { Conv. }}{0,68^{*}}$} & \multirow{2}{*}{$\frac{\mathbf{P V}}{0,69 *}$} & \multirow{2}{*}{$\frac{\text { PVad }}{0,79 * *}$} \\
\hline TF & (2) & & & & & \\
\hline 1 & $\mathrm{C}$ & $0,84 * *$ & $0,70 * *$ & $0,85 * *$ & $0,80 * *$ & $0,80 * *$ \\
\hline & $\begin{array}{l}M \\
P\end{array}$ & $\begin{array}{l}0,80^{* *} \\
0,93 * *\end{array}$ & $\begin{array}{l}0,56 \\
0,90 * *\end{array}$ & $\begin{array}{l}0,18 \\
0,89 * *\end{array}$ & $\begin{array}{l}0,87 * * \\
0,86 * *\end{array}$ & $\begin{array}{l}0,73^{* *} \\
0,86^{* *}\end{array}$ \\
\hline
\end{tabular}

(1) AREIA - areia lavada com inóculo misto de 100 estirpes de rizóbio + adubação (por saco) de: $3 \mathrm{~mL} \mathrm{CaSO}{ }_{4} \mathrm{~mol} \mathrm{~L}^{-1}, 4 \mathrm{~mL}$ de $\mathrm{K}_{2} \mathrm{SO}_{4}$ $\mathrm{mol} \mathrm{L}-1,2 \mathrm{~mL} \mathrm{Na}_{2} \mathrm{HPO}_{4} \mathrm{~mol} \mathrm{~L}^{-1}, 4 \mathrm{~mL} \mathrm{MgSO}_{4} \mathrm{~mol} \mathrm{~L}^{-1}$ e $1 \mathrm{~mL}$ solução demicronutrientes (por litro: $2,86 \mathrm{~g} \mathrm{H}_{3} \mathrm{BO}_{3} ; 1,81 \mathrm{~g} \mathrm{MnCl}_{2} ; 0,22 \mathrm{~g}$ $\mathrm{ZnSO}_{4} \cdot 7 \mathrm{H}_{2} \mathrm{O} ; 0,8 \mathrm{gCuSO}_{4} \cdot 5 \mathrm{H}_{2} \mathrm{O} ; 0,02 \mathrm{~g} \mathrm{MoO}_{3} .2 \mathrm{H}_{2} \mathrm{O}$ e $0,02 \mathrm{~g} \mathrm{CoCl}_{2}$ ); $\mathrm{GH}$ - horizonte $\mathrm{A}$ de solo glei húmico coletado na várzea do Rio Solimões; CONV - substrato convencional de viveiro consistindo de mistura de argila e areia na proporção 3:2 (VN); PV - Horizonte A de podzól ico vermel ho-amarelo col etado na Reserva Floresta Ducke (Manaus) e PVad - substrato PV adubado (por saco) com: $3 \mathrm{~g}$ de calcário dolomítico, 0,2 g de superfosfato simples, 0,2 g de fosfato

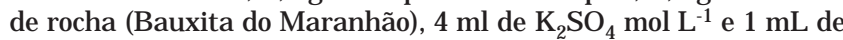
solução de micronutrientes. ${ }^{(2)}$ As 3 subfamílias foram analisadas em conjunto devido ao número reduzido de espécies em cada uma, para análise individual.

* Significativo ao nível de 5\%. ** Significativo ao nível de 1\%.
Algumas espécies, oriundas de áreas inundadas, apresentaram comportamento fisiológico característico de adaptação a seu habitat, perdendo suas fol has em alguns períodos de seu desenvolvimento (e.g. Macrolobium acaciifolium). Porém, as taxas de sobrevivência à repicagem de mudas de todas as espécies não diferiram, significativamente, dependendo de sua origem (terra firme ou áreas inundadas). Dentre os substratos, AREI A apresentou as maiores taxas de mortalidade, em torno de $5 \%$ (Quadro 8), o que pode ser explicado por sua baixa capacidade de retenção de água e de nutrientes.

As áreas inundadas representam $25 \%$ da região amazônica, mas contribuem com $75 \%$ da madeira extraída. Considerando que o desmatamento das várzeas e igapós compromete, seriamente, ciclos biológicos importantes (Walker, 1991), é ecológica e economi camente importante o reflorestamento de áreas já desmatadas com espécies nativas. Estudos posteriores devem pesquisar o comportamento dessas espécies no campo. Leguminosas, como Swartzia polyphylla, Vatairea guianensis, Mora paraensis, e Enterolobium maximum, importantes do ponto de vista de utilização de suas madeiras e de produtos fitoquímicos (Ducke, 1949; Loureiro et al., 1979; Ribeiro et al., 1987) e com al ta taxa decrescimento no viveiro, devem ser consideradas para plantios em larga escala.

Quadro 6. Nodulação de espécies arbóreas, oriundas de áreas periodicamente inundadas da Amazônia, em cinco substratos no viveiro

\begin{tabular}{|c|c|c|c|c|c|c|c|c|c|c|}
\hline \multirow{3}{*}{ Subfamília/E spécie } & \multicolumn{10}{|c|}{ Substrato ${ }^{(1)}$} \\
\hline & \multicolumn{5}{|c|}{ Nódulos } & \multicolumn{5}{|c|}{ Peso de nódulos } \\
\hline & Areia & GH & Conv & PV & PVad & Areia & GH & Conv & PV & PVad \\
\hline \multicolumn{8}{|l|}{ Caesalpinioideae } & $\mathrm{mg}$ & & 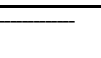 \\
\hline $\begin{array}{c}\text { Campsiandra comosa Bth. F } 312^{(4)} \\
124725 \\
\text { Chamaecrista negrensis Irwin \& Barneby } \\
\text { Tachigali paniculata Aubl. } 138801 \\
138812\end{array}$ & $\begin{array}{l}19,5 \mathrm{a}^{(2)} \\
128,4 \mathrm{a} \\
2,7 \mathrm{~b} \\
6,0 \\
1,8 \mathrm{ab}\end{array}$ & $\begin{array}{l}5,3 \mathrm{ab} \\
30,2 \mathrm{~b} \\
39,8 \mathrm{a} \\
3,0 \\
4,1 \mathrm{a}\end{array}$ & $\begin{array}{l}16,8 \mathrm{ab} \\
\ldots \\
\ldots \\
14,0 \\
\ldots\end{array}$ & $\begin{array}{l}6,7 \mathrm{ab} \\
\ldots \\
\cdots \\
\dddot{1}, 0 \\
1,4 \mathrm{ab}\end{array}$ & $\begin{array}{c}0,8 \mathrm{~b} \\
\ldots 3,2 \mathrm{a} \\
0,0 \\
0,0 \mathrm{~b}\end{array}$ & $\begin{array}{l}62 \mathrm{ab} \\
476 \mathrm{a} \\
9 \mathrm{~b} \\
6 \\
5 \mathrm{ab}\end{array}$ & $\begin{array}{r}12 \mathrm{~b} \\
39 \mathrm{~b} \\
170 \mathrm{a} \\
6 \\
11 \mathrm{a}\end{array}$ & $\begin{array}{l}73 \text { a } \\
\ldots \\
\ldots \\
31 \\
\ldots\end{array}$ & $\begin{array}{l}25 a b \\
\ldots \\
\cdots \\
\ldots \\
5 \\
a b\end{array}$ & $\begin{array}{r}3 \mathrm{~b} \\
286 \mathrm{a} \\
0 \\
0 \mathrm{~b}\end{array}$ \\
\hline \multicolumn{11}{|l|}{ Mimosoideae } \\
\hline $\begin{array}{l}\text { Inga acreanum } \mathrm{H} \text { arms } \\
\text { I. disticha Bth. } \\
\text { Inga sp. } \\
\text { Pentaclethra macroloba (Wiild.) Kuntze }\end{array}$ & $\begin{array}{l}86,9 \text { a } \\
15,5 \text { a } \\
60,0 \text { a } \\
61,2 \text { a }\end{array}$ & $\begin{array}{r}13,0 \mathrm{~b} \\
7,4 \mathrm{a} \\
72,6 \mathrm{a} \\
96,3 \mathrm{a}\end{array}$ & $\begin{array}{l}14,6 \mathrm{~b} \\
20,8 \mathrm{a} \\
77,6 \mathrm{a}\end{array}$ & $\begin{array}{r}3,3 \mathrm{~b} \\
0,3 \mathrm{~b} \\
41,3 \mathrm{a}\end{array}$ & $\begin{array}{c}64,7 \text { a } \\
0 \mathrm{~b} \\
33,6 \mathrm{a} \\
12,1 \mathrm{a}\end{array}$ & $\begin{array}{r}123 \mathrm{~b} \\
8 \mathrm{ab} \\
243 \mathrm{a} \\
395 \mathrm{ab}\end{array}$ & $\begin{array}{l}138 \mathrm{~b} \\
5 \mathrm{abc} \\
262 \mathrm{a} \\
653 \mathrm{a}\end{array}$ & $\begin{array}{r}55 \mathrm{~b} \\
13 \mathrm{a} \\
231 \mathrm{a}\end{array}$ & $\begin{array}{r}29 \mathrm{~b} \\
7 \mathrm{bc} \\
276 \mathrm{a}\end{array}$ & $\begin{array}{r}332 a \\
0 c \\
277 a \\
49 b\end{array}$ \\
\hline $\begin{array}{r}\text { P. arenarium Ducke 133 } 591 \\
\text { F } 327\end{array}$ & $\begin{array}{r}4,1 \text { a } \\
18,6 \text { a }\end{array}$ & $\begin{array}{r}0,5 \mathrm{a} \\
9,8 \mathrm{a}\end{array}$ & $\begin{array}{r}\dddot{2}, 8 \mathrm{a} \\
18,2 \mathrm{a}\end{array}$ & $\dddot{i 1,4}$ a & $\begin{array}{r}2,4 \mathrm{a} \\
6,0 \mathrm{a}\end{array}$ & $\begin{array}{rl}5 a & \\
22 & a\end{array}$ & $\begin{array}{r}3 a \\
18 a\end{array}$ & $\begin{array}{r}9 \\
29 a\end{array}$ & 14 a & $\begin{array}{l}37 a \\
14 a\end{array}$ \\
\hline $\begin{array}{l}\text { P. Iatifolium (L.) Bth. } \\
\text { P. multiflorum (H.B.K.) Bth. } 124726 \\
133635\end{array}$ & $\begin{array}{c}172,4 \mathrm{a} \\
24,4 \mathrm{a} \\
1,0\end{array}$ & $\begin{array}{l}48,4 \text { a } \\
20,0 \text { a } \\
18,9 \text { a }\end{array}$ & $\begin{array}{r}30,2 \mathrm{~b} \\
5,5 \mathrm{~b} \\
18,1 \mathrm{a}\end{array}$ & $\begin{array}{r}17,8 \mathrm{~b} \\
2,8 \mathrm{~b} \\
1,6 \mathrm{~b}\end{array}$ & $\begin{array}{r}30,8 \mathrm{~b} \\
5,5 \mathrm{~b} \\
15,1 \mathrm{a}\end{array}$ & $\begin{aligned} 125 \mathrm{a} \\
12 \mathrm{~b} \\
\ldots\end{aligned}$ & $\begin{array}{r}120 \mathrm{a} \\
54 \mathrm{a} \\
10 \mathrm{ab}\end{array}$ & $\begin{array}{r}57 \mathrm{a} \\
4 \mathrm{~b} \\
8 \mathrm{~b}\end{array}$ & $\begin{array}{r}83 \mathrm{a} \\
2 \mathrm{~b} \\
3 \mathrm{~b}\end{array}$ & $\begin{array}{r}102 \mathrm{a} \\
11 \mathrm{~b} \\
27 \mathrm{a}\end{array}$ \\
\hline $\begin{array}{l}\text { P. sanguineum Bth. } \\
\text { Pithecellobium sp. }\end{array}$ & $\begin{array}{l}49,1 \text { a } \\
61,1 \text { a }\end{array}$ & $\begin{array}{r}2,1 \mathrm{c} \\
87,4 \mathrm{a}\end{array}$ & $\begin{array}{l}21,1 \mathrm{ab} \\
23,6 \mathrm{ab}\end{array}$ & $\begin{array}{l}5,9 \mathrm{bc} \\
4,3 \mathrm{c}\end{array}$ & $\begin{array}{r}7,9 \mathrm{bc} \\
10,9 \mathrm{bc}\end{array}$ & $\begin{array}{l}17 \mathrm{a} \\
94 \mathrm{~b}\end{array}$ & $\begin{aligned} 3 \mathrm{~b} \\
352 \mathrm{a}\end{aligned}$ & $\begin{array}{l}15 \mathrm{a} \\
55 \mathrm{~b}\end{array}$ & $\begin{array}{rl}6 & b \\
26 & b\end{array}$ & $\begin{array}{l}10 \mathrm{ab} \\
115 \mathrm{~b}\end{array}$ \\
\hline \multicolumn{11}{|l|}{ Papilinoideae } \\
\hline Ormosia excelsa bth. & $12,8 \mathrm{a}$ & $0 \mathrm{bc}$ & $2,0 \mathrm{~b}$ & $0 \mathrm{bc}$ & $0 \mathrm{C}$ & 1 a & $0 \mathrm{~b}$ & $5 \mathrm{~b}$ & $0 \mathrm{~b}$ & $0 \mathrm{~b}$ \\
\hline O. macrocalyx Ducke 133851 & $\begin{aligned} 2,0 \\
57,1 \mathrm{a}\end{aligned}$ & $\begin{array}{r}113,3 \mathrm{a} \\
21,2 \mathrm{ab} \\
78,4 \mathrm{a}\end{array}$ & $\begin{array}{l}12,9 a \\
25,9 a b\end{array}$ & $\begin{array}{rl}25,6 & a \\
0,2 & c \\
57,1 & \end{array}$ & $\begin{array}{r}60,2 \mathrm{a} \\
5,8 \mathrm{~b}\end{array}$ & $73 a^{2}$ & $\begin{array}{l}27 a \\
65 a b \\
224 a\end{array}$ & $\begin{array}{l}23 a \\
88 a\end{array}$ & $\begin{array}{rl}74 & \mathrm{a} \\
0 & \mathrm{~b} \\
727 & \end{array}$ & $\begin{array}{l}53 a \\
27 a b \\
753 a\end{array}$ \\
\hline $\begin{array}{l}\text { Swartzia polyphylla DC. } \\
\text { Swartzia sp. } 1\end{array}$ & $\begin{array}{r}158,5 \text { a } \\
9,1 \text { a }\end{array}$ & $\begin{array}{l}18,4 \mathrm{a} \\
(+)^{(3)}\end{array}$ & $\dddot{0,4 b}$ & $\begin{array}{r}5 /, 1 \text { a } \\
5,2 \text { a }\end{array}$ & $\begin{array}{r}44,1 \mathrm{~d} \\
8,1 \mathrm{a}\end{array}$ & $\begin{array}{r}447 \mathrm{ab} \\
73 \mathrm{ab}\end{array}$ & $\begin{array}{r}224 \mathrm{~b} \\
0 \mathrm{~b}\end{array}$ & $a b$ & $\begin{array}{l}721 \mathrm{a} \\
108 \mathrm{a}\end{array}$ & $\begin{array}{r}753 \mathrm{a} \\
57 \mathrm{ab}\end{array}$ \\
\hline Swartzia sp. 2 & $5,3 a$ & $0,0 \mathrm{~b}$ & 8,4 a & $0,0 \mathrm{~b}$ & 3,3 a & & $0 \mathrm{~b}$ & 31 a & $0 \mathrm{~b}$ & $16 \mathrm{a}$ \\
\hline Percentagem de espécies noduladas & 100 & 87 & 100 & 84 & 77 & & & & & \\
\hline
\end{tabular}

(1) AREIA - areia lavada com inóculo misto de 100 estirpes de rizóbio + adubação (por saco) de: $3 \mathrm{~mL} \mathrm{CaSO} \mathrm{mol} \mathrm{L}^{-1}, 4 \mathrm{~mL}$ de $\mathrm{K}_{2} \mathrm{SO}_{4}$ $\mathrm{mol} \mathrm{L}^{-1}, 2 \mathrm{~mL} \mathrm{Na}_{2} \mathrm{HPO}_{4} \mathrm{~mol} \mathrm{~L}^{-1}, 4 \mathrm{~mL} \mathrm{MgSO}_{4} \mathrm{~mol} \mathrm{~L}^{-1} \mathrm{e} 1 \mathrm{~mL}$ solução de micronutrientes (por litro: $2,86 \mathrm{~g} \mathrm{H}_{3} \mathrm{BO}_{3} ; 1,81 \mathrm{~g} \mathrm{MnCl}_{2} ; 0,22 \mathrm{~g}$ $\mathrm{ZnSO}_{4} .7 \mathrm{H}_{2} \mathrm{O} ; 0,8 \mathrm{~g} \mathrm{CuSO}_{4} \cdot 5 \mathrm{H}_{2} \mathrm{O} ; 0,02 \mathrm{~g} \mathrm{MoO}_{3} \cdot 2 \mathrm{H}_{2} \mathrm{O}$ e $\left.0,02 \mathrm{~g} \mathrm{CoCl}_{2}\right) ; \mathrm{GH}$ - horizonte A de solo glei húmico col etado na várzea do Rio Solimổes; CONV - substrato convencional de viveiro consistindo de mistura de argila e areia na proporção 3:2 (VN); PV - Horizonte A de podzólico vermel ho-amarelo coletado na Reserva Floresta Ducke (Manaus) e PVad - substrato PV adubado (por saco) com: $3 \mathrm{~g}$ de calcário dolomítico, 0,2 g de superfosfato simples, 0,2 g de fosfato de rocha (Bauxita do Maranhão), $4 \mathrm{ml} \mathrm{de}{ }_{2} \mathrm{SO}_{4} \mathrm{~mol} \mathrm{~L}^{-1}$ e $1 \mathrm{~mL}$ de solução de micronutrientes. (2) Médias (de 5 plantas) seguidas por letras distintas na mesma linha diferem entre si ao nível de $5 \%$ pelo teste de Duncan. (3) Nódulos presentes mas não avaliados. (4) № registro no herbário das diferentes procedências da espécie

Obs.: A procedência 124726 de Pithecel lobium multifl orum nodul ou no substratoAREIA ePithecel lobium adiatifolium nodul ou nos substratos AREIA e CONV e não nodulou em PVad. As espécies dos gêneros nodulíferos Sclerol obium e Swartzia (S. sp 3) não nodularam no viveiro. 
Quadro 7. Nodulação de espécies de leguminosas arbóreas, oriundas de terra firme da Amazônia, em cinco substratos no viveiro

\begin{tabular}{|c|c|c|c|c|c|c|c|c|c|c|}
\hline \multirow{3}{*}{ Subfamília/E spécie } & \multicolumn{10}{|c|}{ Substrato $^{(1)}$} \\
\hline & \multicolumn{5}{|c|}{ Nódulos } & \multicolumn{5}{|c|}{ Peso de nódulos } \\
\hline & Areia & GH & Conv & PV & PVad & Areia & GH & Conv & PV & PVad \\
\hline & & & $-\mathrm{n}^{\circ}-$ & 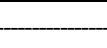 & - & 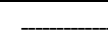 & 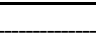 & $-m g$ & 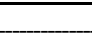 & 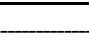 \\
\hline \multicolumn{11}{|l|}{ Mimosoideae } \\
\hline $\begin{array}{l}\text { Calliandra tenuiflora Bth. } \\
\text { Enterol obi um maximum }\end{array}$ & $0 b^{(2)}$ & $0,3 a$ & $0 \mathrm{~b}$ & $0 \mathrm{~b}$ & $0 \mathrm{~b}$ & $O b$ & $9 a$ & $0 \mathrm{~b}$ & $0 \mathrm{~b}$ & $0 \mathrm{~b}$ \\
\hline Ducke & $51,6 a$ & $11,1 \mathrm{~b}$ & $10,8 b$ & $1,0 \mathrm{c}$ & $0,2 \mathrm{c}$ & $147 a$ & $40 \mathrm{bc}$ & $95 a b$ & $18 \mathrm{bc}$ & $4 c$ \\
\hline $\begin{array}{l}\text { Inga cal antha Ducke } \\
\text { Inga ingoides (Rich.) }\end{array}$ & $0,4 b$ & $2,8 a$ & $4,6 a$ & $0 \mathrm{~b}$ & $44,4 \mathrm{a}$ & $2 b$ & $3 b$ & $7 a b$ & $\mathrm{Ob}$ & $15 a$ \\
\hline Willd & $2,6 a b$ & $3,2 a b$ & $1,1 b$ & $6,3 a$ & $2,7 a b$ & $7 a$ & $6 a$ & $7 a$ & $15 a$ & $19 a$ \\
\hline Inga sp. 1 & 2 & 4 & 2 & 1 & 0 & 6 & 10 & 3 & 2 & 0 \\
\hline Inga sp. 2 & 2 & $(+)^{(3)}$ & 1 & 0 & 6 & 2 & $\ldots$ & 2 & 0 & 14 \\
\hline Pithecel lobium caul iflorum (Wild) Bth. & $54,6 a$ & 13,4 bc & $24,6 a b$ & $11,6 b c$ & $5,8 \mathrm{c}$ & $33 a$ & $12 b$ & $33 a$ & $22 a b$ & $12 \mathrm{~b}$ \\
\hline Strypnodendron sp. & $2,5 \mathrm{ab}$ & $0,2 \mathrm{~b}$ & $3,6 a$ & $0,2 b$ & $\mathrm{Ob}$ & $6 \mathrm{ab}$ & $\ldots$ & $19 a$ & $1 \mathrm{~b}$ & $0 \mathrm{~b}$ \\
\hline \multicolumn{11}{|l|}{ Papilinoideae } \\
\hline Andira micrantha Ducke & $13,4 a$ & $0,3 b$ & $\ldots$ & $\ldots$ & $\ldots$ & $139 a$ & $11 \mathrm{a}$ & $\ldots$ & $\ldots$ & $\ldots$ \\
\hline $\begin{array}{l}\text { Dal bergia sp. } \\
\text { Platymiscium ducké }\end{array}$ & $(+)$ & 0 & 0 & 0 & $(+)$ & $\ldots$ & 0 & 0 & 0 & $\ldots$ \\
\hline Huber & $45,5 a$ & $15,5 b$ & $1,52 \mathrm{c}$ & $0,15 \mathrm{c}$ & $0,24 \mathrm{c}$ & $64 a$ & $5,6 a$ & $7 \mathrm{~b}$ & $1 \mathrm{~b}$ & $2 \mathrm{~b}$ \\
\hline Percentagem de espécies noduladas & 91 & 91 & 80 & 60 & 70 & & & & & \\
\hline
\end{tabular}

(1) AREIA - areia lavada com inóculo misto de 100 estirpes de rizóbio + adubação (por saco) de: $3 \mathrm{~mL} \mathrm{CaSO} \mathrm{mol} \mathrm{L}^{-1}, 4 \mathrm{~mL}$ de $\mathrm{K}_{2} \mathrm{SO}_{4}$ mol L-1, $2 \mathrm{~mL} \mathrm{Na}_{2} \mathrm{HPO}_{4} \mathrm{~mol} \mathrm{~L}^{-1}, 4 \mathrm{~mL} \mathrm{MgSO}_{4} \mathrm{~mol} \mathrm{~L}^{-1}$ e $1 \mathrm{~mL}$ solução de micronutrientes (por litro: $2,86 \mathrm{~g} \mathrm{H}_{3} \mathrm{BO}_{3} ; 1,81 \mathrm{~g} \mathrm{MnCl}_{2} ; 0,22 \mathrm{~g}$ $\mathrm{ZnSO}_{4} \cdot 7 \mathrm{H}_{2} \mathrm{O} ; 0,8 \mathrm{~g} \mathrm{CuSO}_{4} \cdot 5 \mathrm{H}_{2} \mathrm{O} ; 0,02 \mathrm{~g} \mathrm{MoO}_{3} \cdot 2 \mathrm{H}_{2} \mathrm{O}$ e $\left.0,02 \mathrm{~g} \mathrm{CoCl}_{2}\right) ; \mathrm{GH}$ - horizonte A de solo glei húmico coletado na várzea do Rio Solimões; CONV - substrato convencional de viveiro consistindo de mistura de argila e areia na proporção 3:2 (VN); PV - H orizonte A de podzólico vermelho-amarelo coletado na Reserva Floresta Ducke (Manaus) e PVad - substrato PV adubado (por saco) com: $3 \mathrm{~g}$ de calcário dolomítico, 0,2 g de superfosfato simples, 0,2 g de fosfato de rocha (Bauxita do Maranhão), $4 \mathrm{ml} \mathrm{de} \mathrm{K}_{2} \mathrm{SO}_{4} \mathrm{~mol} \mathrm{~L}^{-1}$ e $1 \mathrm{~mL}$ de solução de micronutrientes. (2) Médias (de 5 plantas) seguidas por letras distintas numa mesma linha diferem entre si ao nível de $5 \%$ pelo teste de Duncan. (3) Nódulos presentes, porém não houve avaliação.

Obs.: Andira inermis foi observada com nódulos no campo, mas não nodulou no viveiro.

Quadro 8. Sobrevivência de 33 espécies de leguminosas, oriundas de áreas inundadas (I), e de 16 espécies, oriundas de terra firme (TF ), após transplante de plântulas, obti das por germi nação em caixas de areia, para diferentes substratos, no viveiro

\begin{tabular}{|c|c|c|c|c|c|c|c|c|}
\hline \multirow{2}{*}{$\begin{array}{l}\text { Origemdas } \\
\text { espécies }\end{array}$} & \multicolumn{8}{|c|}{ Substrato ${ }^{(1)}$} \\
\hline & & & Areia & GH & Conv & PV & PVad & Total \\
\hline I & $\begin{array}{l}\text { № total de plântulas } \\
\text { Indivíduos mortos }\end{array}$ & $\begin{array}{l}\mathrm{N}^{\circ} \\
\%\end{array}$ & $\begin{array}{c}473 \\
22 \\
4,6\end{array}$ & $\begin{array}{c}423 \\
16 \\
3,8\end{array}$ & $\begin{array}{c}312 \\
4 \\
1,3\end{array}$ & $\begin{array}{c}291 \\
11 \\
3,8\end{array}$ & $\begin{array}{c}399 \\
15 \\
3,8\end{array}$ & $\begin{array}{c}1898 \\
68 \\
3,6\end{array}$ \\
\hline TF & $\begin{array}{l}\text { № total de plântulas } \\
\text { Indivíduos mortos }\end{array}$ & $\begin{array}{l}\text { № } \\
\%\end{array}$ & $\begin{array}{r}161 \\
8 \\
5,0\end{array}$ & $\begin{array}{c}173 \\
3 \\
1,7\end{array}$ & $\begin{array}{c}136 \\
7 \\
5,2\end{array}$ & $\begin{array}{c}149 \\
7 \\
4,7\end{array}$ & $\begin{array}{c}148 \\
4 \\
2,7\end{array}$ & $\begin{array}{c}767 \\
29 \\
3,8\end{array}$ \\
\hline
\end{tabular}

(1) AREIA - areia lavada com inóculo misto de 100 estirpes de rizóbio + adubação (por saco) de: $3 \mathrm{~mL} \mathrm{CaSO}_{4} \mathrm{~mol} \mathrm{~L}^{-1}, 4 \mathrm{~mL}$ de $\mathrm{K}_{2} \mathrm{SO}_{4}$ mol L-1, $2 \mathrm{~mL} \mathrm{Na}_{2} \mathrm{HPO}_{4}$ mol L-1, $4 \mathrm{~mL} \mathrm{MgSO}_{4} \mathrm{~mol} \mathrm{~L}^{-1}$ e $1 \mathrm{~mL}$ solução de micronutrientes (por litro: $2,86 \mathrm{~g} \mathrm{H}_{3} \mathrm{BO}_{3} ; 1,81 \mathrm{~g} \mathrm{MnCl}_{2} ; 0,22 \mathrm{~g}$ $\mathrm{ZnSO}_{4} \cdot 7 \mathrm{H}_{2} \mathrm{O} ; 0,8 \mathrm{~g} \mathrm{CuSO}_{4} \cdot 5 \mathrm{H}_{2} \mathrm{O} ; 0,02 \mathrm{~g} \mathrm{MoO}_{3} \cdot 2 \mathrm{H}_{2} \mathrm{O}$ e $0,02 \mathrm{~g} \mathrm{CoCl}_{2}$ ); $\mathrm{GH}$ - horizonte A de solo glei húmico coletado na várzea do Rio Solimões; CONV - substrato convencional de viveiro consistindo de mistura de argila e areia na proporção 3:2 (VN); PV - H orizonte A de podzólico vermelho-amarelo coletado na Reserva Floresta Ducke (Manaus) e PVad - substrato PV adubado (por saco) com: $3 \mathrm{~g}$ de calcário dolomítico, 0,2 g de superfosfato simples, 0,2 g de fosfato de rocha (Bauxita do Maranhão), $4 \mathrm{ml} \mathrm{de} \mathrm{K}_{2} \mathrm{SO}_{4} \mathrm{~mol} \mathrm{~L}^{-1}$ e $1 \mathrm{~mL}$ de solução de micronutrientes. 


\section{CONCLUSÕES}

1. Algumas espécies cresceram melhor nos substratos de maior fertilidade: GH ePVad, indicando que são mais exigentes em termos nutricionais.

2. As espécies oriundas de áreas inundadas apresentaram taxas de crescimento maiores que as oriundas de terra firme.

3. De modo geral, houve correlação significativa entre tamanho de sementes e crescimento em altura das espécies nos cinco substratos.

4. As espécies estudadas apresentaram alto índice desobrevivência após transplante desementeira para os substratos no viveiro.

5. O melhor substrato para crescimento dessas espécies foi o $\mathrm{GH}$ e, para nodulação, o substrato AREIA.

\section{LITERATURA CITADA}

AUNG, L.H. Root-shoot relationships. In: CARSON, E.W., ed. The plant root and its environment. Charlotlesville University Press of Virginia, 1978. p.29-61.

DILWORTH, M.J. Acetylene reduction by nitrogen-fixing preparations from Clostridium pasteurianum. Biochem. Biophys. Acta., Amsterdam, 127:285-294, 1966.

DUCKE, A. Notas sobre a flora neotrópica. II. As leguminosas da Amazônia Brasileira, Belém, IAN, 1949. p. 1-249. (Boletim Técnico, 18)

FERNANDES, N. \& SAMPAIO, P.T.B. Silvicultura de espécies florestais (Plantios). In: VAL, A.L.; FIGLIUOLO, R. \& FELDBERG, E. eds. Bases científicas para estratégias de preservação e desenvolvimento da Amazônia. Manaus, I NPA, 1991. v.1. p. 207-213.

FRANCO, A.A. \& FARIA, S.M. The contribution of nitrogen-fixing trees to land reclamation and sustainability in the tropics. In: INTERNATIONAL SYMPOSIUM ON SUSTAINABLE AGRICULTURE FOR THE TROPICS - THE ROLE OF BIOLOGICAL NITROGEN FIXATION, Angra dos Reis, 1995. Abstracts, Angra dos Reis, EMBRAPA-CNPAB, 1995, p.44.

J ANSEN, M.R.A. \& ALENCAR, J.C. Contribuição à reposição florestal no estado doAmazonas. In:VAL,A.L.; FIGLIUOLO, R. \& FELDBERG, E. eds. Bases científicas para estratégias de preservação e desenvolvimento da Amazônia. Manaus, INPA, 1991. v.1. p.187-205.
LOUREIRO, A.; SILVA, M.F. \& ALENCAR, J.C. Essências madeireiras da Amazônia. I NPA/SUF RAMA. 1979. v.1. 245p.

LOUREIRO, A.; SILVA, M.F. \& ALENCAR, J.C. Essências madeireiras da Amazônia. I NPA/SUFRAMA. 1979. v.2. 187p.

MCKEY, D.M. Legumes and nitrogen: The evolutionary ecology of a nitrogen-demanding lifestyle. In: SPRENT, J I . \& MCKEY, D.M., eds. Advances in legume systematics. 5. The nitrogen factor. Kew, Royal Botanic Gardens, 1994. p.211-228.

MOREIRA, F.M.S. Caracterização de estirpes de rizóbio isoladas de espécies florestais pertencentes a diversos grupos de divergência de Leguminoseae introduzidas ou nativas da Amazônia e Mata Atlântica. Rio de J aneiro, UFRRJ , 1991. (Tese de Doutorado)

MOREIRA, F.M.S. Nodulação e crescimento de leguminosas em dois solos da Amazônia. R. bras. Ci. Solo, Campinas, 19:197204, 1995.

MOREIRA, F.M.S. \& MOREIRA, F.W. Características da germinação de sementes de 64 espécies de leguminosas florestais nativas da Amazônia, em condições de viveiro. Acta Amazôn., Manaus, 26:3-16, 1996.

MOREIRA, F.M.S.; GILLIS, M.; POT, B.; KERSTERS, K. \& FRANCO, A.A. Characterization of rhizobia isolated from different divergence groups of tropical Leguminosae by comparative polyacrylamide gel electrophoresis of their total proteins. System. Appl. Microbiol., Washington, 16:135-146, 1993.

RIBEIRO, M. N.S.; ZOGHBI, M.G.B.; SILVA, M.L.; GOTTLIEB, O.R. \& REZE NDE, C.M.M. Cadastro fitoquímico brasileiro. Manaus, INPA/FUA, 1987. 112p.

SARRIÉS, G.A.; OLIVEIRA, J.V.C. \& ALVES, M.C. SANEST, Piracicaba, CIAGRI, 1992. 80 p. (Série Didática CIAGRI, 6)

SILVA, M.F.; GOLDMAN, G.H.; MAGALHÃES, F.M.M. \& MOREIRA, F.W. Germinação natural de 10 leguminosas arbóreas da Amazônia I . Acta Amaz., Manaus, 18:9-26, 1988.

SPRENT, J I. Nitrogen acquisition systems in the Leguminosae. In: SPRENT, J.I . \& McKEY, D.M., eds. Advances in legum systematics; the nitrogen factor. Parte 5. Kew, Royal Botanic Gardens, 1994. p.1-16.

VINCENT, J.M.A manual for the practical study of the root nodule bacteria. Oxford, Blackwell Scientific Publications, 1970. $164 p$.

WALKER, I. Algumas considerações sobre um programa de zoneamento da Amazônia. In: VAL, A.L.; FIGLIUOLO, R. \& FELDBERG, E. eds. Bases científicas para estratégias de preservação e desenvol vimento da Amazônia. Manaus, INPA, 1991. v.1. p.37-46. 